\title{
An Investigation on Current Work Situation of Psychological Teachers in Primary and Secondary School
}

\author{
Naiyi Wang, Fulin Fan, Ping Li \\ Institute of Educational Psychology and School Counseling, Faculty of Education, Beijing Normal University, Beijing, China \\ wangnaiyi@bnu.edu.cn
}

\begin{abstract}
Understanding psychological teachers' current work situation is a prerequisite of improving the level of mental health education in primary and secondary school. Using questionnaires developed by Institute of Educational Psychology and School Counseling of Beijing Normal University, the study surveyed 103 psychological teachers and 16954 students from 72 primary and secondary schools of eight provinces/cities in China. It focused on four aspects referring to psychological teachers' work situation: the basic information of psychological teachers, their work content and time distribution, the professional training system, and the student feedback for mental health education. Based on the survey results, recommendations were put forward, including increasing the number of full-time psychological teachers, strengthening the in-service professional training, as well as expanding the influence of school mental health education.
\end{abstract}

Index Terms - psychological teachers, primary and secondary school, current work situation, student feedback

\section{Introduction}

In recent years, psychological problems of primary and secondary school students are on the rise. To improve the situation, it needs close cooperations among schools, families, and society [1]. Above all, building up high qualified ranks of psychological teachers is the key. Having a comprehensive understanding of the psychological teachers' current work situation as well as its development needs is a prerequisite of improving the level of mental health education in primary and secondary school. To this end, the Institute of Educational Psychology and School Counseling of Beijing Normal University conducted a comprehensive survey on the mental health education in a group of primary and secondary schools. These schools were drawn from eight provinces/cities across China by stratified sampling. The article focused on four aspects referring to psychological teachers' current work situation: the basic information of psychological teachers, their work content and time distribution, the professional training system, and the student feedback for mental health education. The results provided a basis to improve the professional level and effectiveness of the school mental health education.

\section{II . Method}

\section{A. Participants}

School administrators, full-time and part-time psychological teachers, class teachers and students from 72 primary (Grade 4-6 only) and secondary schools participated in the survey. The schools were sampled from eight provinces/cities with various economic development levels: Beijing, Jilin Province, Xinjiang Province, Sichuan Province,
Hebei Province, Guangdong Province, Henan Province, and Yunnan Province. Due to the purpose of this article, only the questionnaires for psychological teachers and students were analyzed. Finally, 144 psychological teacher questionnaires and 20340 student questionnaires were retrieved. Among these, 103 psychological teacher questionnaires $(71.5 \%)$ and 16954 student questionnaires (83.4\%) were valid.

\section{B. Measures}

The set of questionnaires were developed by the Institute of Educational Psychology and School Counseling, Beijing Normal University. The psychological teacher questionnaire included nine items about personal information and 52 items concerning three dimensions: work content, work time distribution, and the professional training system. The students questionnaire included 10 items about personal information and 28 items concerning two dimensions: overall evaluations of individual counseling and mental health curriculum, and ways of resolving psychological problems.

C. Procedure and Data analyses

In this study, data were collected mainly through questionnaire survey, as well as through interview and observation of the mental health education activities. Excel2007 and SPSS18.0 were used for data processing and analyses.

\section{Results}

\section{A. Basic information of the psychological teachers}

1) General characteristics of the psychological teachers The general characteristics of the psychological teachers participated in this research were shown in Table 1. In terms of gender, male and female psychological teachers amount to $20.8 \%$ and $78.2 \%$ respectively, with a male-to-felmale ratio of $1: 4$. There is a noticeable gender difference in the psychological teachers, which is in line with the results of previous domestic investigations [2,3], as well as the situation in the United States [4]. The average age of the psychological teachers is 33.9 years, being generally young in age. Concerning seniority, $34.3 \%$ of the psychological teachers have been engaged in mental health education less than five years. This failed to meet the UNESCO requirement that school counselors must have teaching experiences of more than 5 years. Concerning the title, most psychological teachers are entitled between the primary first level and the secondary first level. Single sample chi-square tests were conducted to examine the distribution of the general characteristics. The 
results showed significant differences in the distribution of all four characteristics (chi-square values ranged from 36.264 to $74.175, p s<.001)$.

TABLE 1 General characteristics of the psychological teachers

\begin{tabular}{|c|c|c|c|}
\hline Basic information & Group & $\mathrm{N}$ & Percent $(\%)$ \\
\hline \multirow{3}{*}{ Gender } & Male & 22 & 20.8 \\
\hline \multirow{4}{*}{ Age } & Female & 84 & 79.2 \\
\cline { 2 - 4 } & $<25$ years & 1 & 1.0 \\
\cline { 2 - 4 } & $26-35$ years & 68 & 64.8 \\
\cline { 2 - 4 } & $36-45$ years & 27 & 25.7 \\
\cline { 2 - 4 } & $>45$ years & 9 & 8.6 \\
\hline \multirow{4}{*}{ Seniority } & $<5$ years & 35 & 34.3 \\
\cline { 2 - 4 } & 5-10 years & 42 & 41.2 \\
\cline { 2 - 4 } & $11-15$ years & 20 & 19.6 \\
\cline { 2 - 4 } & $>16$ years & 5 & 4.9 \\
\hline \multirow{5}{*}{ Title } & Primary second level & 1 & 1.0 \\
\cline { 2 - 4 } & Primary first level & 19 & 19.0 \\
\cline { 2 - 4 } & Primary senior level & 12 & 12.1 \\
\cline { 2 - 4 } & Secondary second level & 31 & 31.3 \\
\cline { 2 - 4 } & Secondary first level & 30 & 30.3 \\
\cline { 2 - 4 } & Secondary senior level & 5 & 5.1 \\
\cline { 2 - 4 } & Secondary special grade & 1 & 1.0 \\
\hline
\end{tabular}

\section{2) Professional level of the psychological teachers}

From Table 2, we can see that the academic qualifications of the psychologcial teachers are generally high, $83.8 \%$ of them having bachelor or higher degrees. But when it comes to professional educational background, only $8.7 \%$ of the psychological teachers majored in mental health education, and $29.8 \%$ majored in psychology. Further, $45.5 \%$ of the psychological teachers do not possess the national certificate of psychological consultants. In addition, full-time psychological teachers in primary and secondary school only amount to $48.0 \%$.

TABLE 2 Professional qualities of the psychological teachers

\begin{tabular}{|c|c|c|c|c|c|}
\hline \multirow[b]{2}{*}{ Variable } & \multirow[b]{2}{*}{ Group } & \multicolumn{3}{|c|}{ School stage } & \multirow[b]{2}{*}{$\begin{array}{l}\text { Percent } \\
(\%)\end{array}$} \\
\hline & & Primary & $\begin{array}{l}\text { Junior } \\
\text { high }\end{array}$ & $\begin{array}{c}\text { Senior } \\
\text { high }\end{array}$ & \\
\hline \multirow{3}{*}{ Major } & $\begin{array}{l}\text { Mental health } \\
\text { education }\end{array}$ & 2 & 7 & 0 & 8.7 \\
\hline & Psychology & 8 & 8 & 15 & 29.8 \\
\hline & Others & 27 & 21 & 15 & 61.5 \\
\hline \multirow{3}{*}{$\begin{array}{l}\text { Academic } \\
\text { qulification }\end{array}$} & College degree & 4 & 4 & 0 & 8.1 \\
\hline & Bachelor degree & 31 & 27 & 28 & 83.8 \\
\hline & $\begin{array}{c}\text { Graduate degree } \\
\text { or above }\end{array}$ & 2 & 4 & 3 & 8.1 \\
\hline \multirow{3}{*}{$\begin{array}{c}\text { Psychological } \\
\text { onsultant } \\
\text { certificate }\end{array}$} & None & 14 & 17 & 14 & 45.5 \\
\hline & Level Three & 11 & 8 & 5 & 24.2 \\
\hline & Level Two & 10 & 9 & 10 & 29.3 \\
\hline \multirow{2}{*}{ Post } & Full-time & 17 & 14 & 17 & 48.0 \\
\hline & Part-time & 19 & 20 & 13 & 52.0 \\
\hline
\end{tabular}

A chi-square test was conducted on the cross table of psychological teachers' major and school stage (primary, junior and senior high school). The results showed that there are significantly differences in the distribution of the teachers' majors among different school stages $\left(\chi^{2}=14.596, p<.01\right)$. Further comparisons of the adjusted residuals showed that junior high school teachers who majored in mental health education was significantly more than senior high school teachers with the same major.

\section{B. Work content and time distribution}

\section{1) Work content of psychological teachers}

The work contents of psychological teachers were shown in Table 3. Most (78.2\%) psychological teachers' daily work involves individual and group counseling. The average frequency of individual counseling is 27 times per semester. Mental health curriculum and lectures is the secondly main work content, which is included in $76.2 \%$ of the psychological teachers's daily work. Besides these two traditional work contents, psychological teachers' daily work also includes helping other teachers with mental health education, mental health education for parents, and mental health-related club activities and the campus cultural construction, and so forth. Hence, the work contents of the psychological teachers in primary and secondary school present a multiple trend.

TABLE 3 Work contents of the psychological teachers

\begin{tabular}{|c|c|c|c|}
\hline Work contents & $\mathrm{N}$ & $\begin{array}{l}\text { Percent } \\
(\%)\end{array}$ & $\begin{array}{c}\text { Percent of } \\
\text { cases }(\%)\end{array}$ \\
\hline 1. Individual and group counseling & 79 & 18.3 & 78.2 \\
\hline 2. Mental health curriculum and lectures & 77 & 17.9 & 76.2 \\
\hline $\begin{array}{l}\text { 3. Help other teachers with mental health } \\
\text { education }\end{array}$ & 65 & 15.1 & 64.4 \\
\hline 4. Mental health education for parents & 43 & 10.0 & 42.6 \\
\hline $\begin{array}{l}\text { 5. Mental health-related club activities and the } \\
\text { campus cultural construction }\end{array}$ & 48 & 11.1 & 47.5 \\
\hline $\begin{array}{l}\text { 6. Management and propaganda of } \\
\text { mental health education }\end{array}$ & 58 & 13.5 & 57.4 \\
\hline $\begin{array}{l}\text { 7. Organization of social resources to } \\
\text { participate in school mental health education }\end{array}$ & 28 & 6.5 & 27.7 \\
\hline 8. Maintain other teachers' mental health & 33 & 7.7 & 32.7 \\
\hline Total & 431 & 100.0 & 426.7 \\
\hline
\end{tabular}

\section{2) Work time distribution of the psychological teachers}

The results showed that for both full-time and part-time psychological teachers, $90 \%$ of them have to be engaged in other work excepte for mental health education. For instance, some of them teach subjects other than mental health (e.g., ideological and ethical education, politics, etc.), work as the calss teacher, participate in the Young Pioneers or the Youth League activities, or engage in moral education. Only $2.9 \%$ of the psychological teachers could pay full attention to school mental health education. The additional work brings psychological teachers mental load. More than half (54\%) of psychological teachers thought their workloads were heavier than other subject teachers, and $35 \%$ of them reported that they were under high work stress.

\section{The professional training system}

Concerning the professional training system of the psychological teachers, the survey data consisted of two parts: research projects and training needs. The percentages of the psychological teachers who had taken part in mental health-related research projects of various levels in the last three years was shown in Fig. 1. Only a small part of the psychological teachers had participated in different kinds of 
research projects, while $54.5 \%$ of them did not take part in any research project.

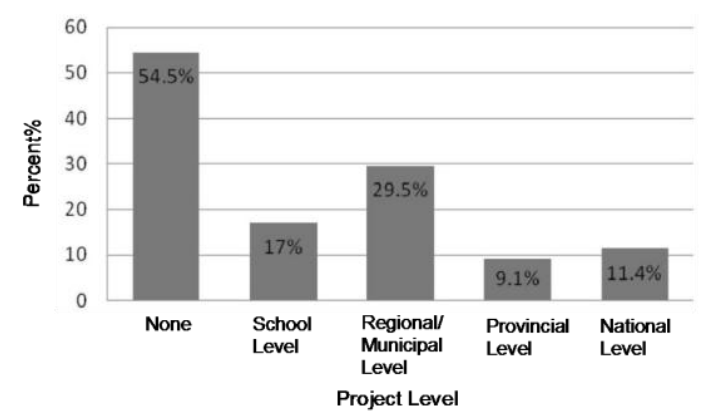

Fig. 1 Percentages of the psychological teachers who had attended mental health-related research projects of various levels in the last three years

The average number of times of professional training that the psychological teachers participated in during the last academic year is four, and $68.7 \%$ of the psychological teachers thought their opportunities to enroll in training classes and seminars were less than other subject teachers. Most psychological teachers expected to improve their various professional qualities through trainings (see Fig. 2). Among those qualities, family counseling was of the greatest demand $(70.1 \%)$.

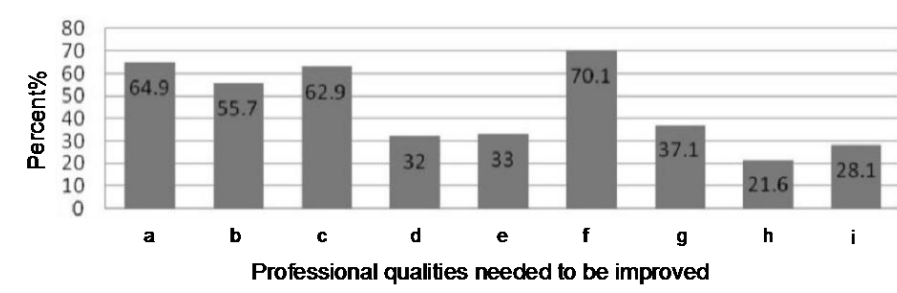

a: Individual counseling; b:Group counseling; c: Curriculum design and implementation; d: Academic development counseling; e: Career development counseling; f. Family counseling; $g$ : Training and counseling for other teachers; $h$ : Work planning and organization; i: Work evaluation and research

Fig. 2 Frequency statistics of the professional qualities which the psychological teachers expected to improve through trainings

\section{Student feedback for mental health education}

1) Students' overall evaluations of individual counseling and mental health curriculum

Individual counseling and mental health curriculum are the two main jobs of psychological teachers. The students' overall evaluations of them were shown in Table 4. In general, positive comments were more than negative ones. Chi-square tests were carried out on the cross tables of student evaluaions and school level (high, medium, low). The results showed that the student evaluations distributed differently in schools of different level $\left(\chi_{\text {conseling }}^{2}=85.083, p<.001 ; \chi_{\text {curriculum }}^{2}=268.647\right.$, $p<.001)$. Further comparisons of adjusted residuals in the cross tables revealed that in terms of "very satisfied" evaluation on both counseling and the curriculum, high level schools were significantly more than medium and low level schools. Whereas, as for "not satisfied" evaluation on both counseling and the curriculum, low level schools were significantly more than medium and high level schools.
TABLE 4 Students' overall evaluations of individual counseling and mental health curriculum

\begin{tabular}{|c|c|c|c|c|}
\hline \multirow{2}{*}{$\begin{array}{c}\text { Overall } \\
\text { evaluations }\end{array}$} & \multicolumn{2}{|c|}{ Individual counseling } & \multicolumn{2}{c|}{ Mental health curriculum } \\
\cline { 2 - 5 } & $\mathrm{N}$ & Percent (\%) & $\mathrm{N}$ & Percent (\%) \\
\hline Very satisfied & 2920 & 36.5 & 2654 & 32.7 \\
\hline Satisfied & 2236 & 28.0 & 3474 & 42.8 \\
\hline Less satisfied & 198 & 2.5 & 353 & 4.3 \\
\hline Not satisfied & 212 & 2.7 & 152 & 1.9 \\
\hline
\end{tabular}

\section{2) Ways of resolving psychological problems}

The ways that primary and secondary school students chose to resovle their psychological problems were shown in Table 5. In general, "self-adjustment" and "talk to friends" were the two most used ways. In contrast, only $15.8 \%$ of the students chose "resort to psychological counseling". A chi-square test was carried out on the cross table of ways and school stage (primary, junior and senior high school). The results showed that the distribution of the psychological problem resolving ways among different school stages were significantly different ( $\left.x^{2}=306.970, \quad p<.001\right)$. Further comparisons of the adjusted residuals in the cross table revealed that in terms of "resort to psychological counseling", primary and junior high school students were significantly more than senior high school students. Besides, it is noteworthy that for both "self-adjustment" and "talk to friends", senior high school students were significantly more than primary and junior high school students.

TABLE 5 Ways students chose to resolve their psychological problems

\begin{tabular}{|l|c|c|c|}
\hline \multicolumn{1}{|c|}{ Problem solving ways } & $\mathrm{N}$ & Percent (\%) & $\begin{array}{c}\text { Percent of } \\
\text { cases (\%) }\end{array}$ \\
\hline 1. Self-adjustment & 11010 & $32.5 \%$ & 69.4 \\
\hline 2. Talk to friends & 9834 & $29.1 \%$ & 62.0 \\
\hline 3. Discuss with family & 5890 & $17.4 \%$ & 37.1 \\
\hline $\begin{array}{l}\text { 4. Resort to psychological } \\
\text { counseling }\end{array}$ & 2512 & $7.4 \%$ & 15.8 \\
\hline 5. Resort to class teacher & 2184 & $6.5 \%$ & 13.8 \\
\hline 6. Resort to other teachers & 941 & $2.8 \%$ & 5.9 \\
\hline 7. Other ways & 1461 & $4.3 \%$ & 9.2 \\
\hline \multicolumn{1}{|c|}{ Total } & 33832 & 100.0 & 213.2 \\
\hline
\end{tabular}

\section{Discussion and recommendation}

To sum up, the results of this study indicated that the mental health education in primary and secondary school of China has made great progress in various aspects. However, with respect to psychological teachers, there are still some problems in aspects such as faculty construction, professional training, and the work influence and effectiveness, compared with other subject teachers. These problems impede and restrict the sustainable development of the mental health education in primary and secondary schools, and need to be further improved by relevant state departments and our schools. For that reason, several recommendations were put forward based on the above results. 
A. Improve the construction of full-time psychological teachers' team, define the psychological teachers' professional functions

The survey data showed that at present, full-time psychological teachers are less than part-time ones in the mental health education team in primary and secondary schools of China. Moreover, the psychological teachers have relatively low seniority and are generally young in age, which means lacking of experiences. Thus, the psychological teacher team of primary and secondary schools in our country is still in its infancy. The present study showed that on average each school has one full-time and four part-time psychological teachers. The American School Counselors Association (ASCA, 2007) suggests an ideal counselor-student proportion of 1:100 or a maximal proportion of 1:300 [5]. And the actual national counselor-to-student ratio is about 1:476 (U. S. Department of Education, 2008). According to this standard, there is a remarkable shortage of full-time school psychological teachers in our country. Therefore, we suggest that schools should greatly increase the positions for full-time psychological teachers. Schools at different levels should recruit teachers with relevant psychological knowledge and skills according to the school's specific needs.

Moreover, the study showed that $90 \%$ of the psychological teachers had to participate in other work than mental health education, which brought extra work load and stress. Therefore, schools should define the professional functions of the psychological teachers more clearly, relieve them from various irrelevant work, and thus ensure the quality of their professional work.

B. Strengthen the in-service professional training, raise scientific research level of the psychological teachers

Despite the fact that the psychological teachers' academic qualifications are generally high, more than half of them did not major in mental health education or psychology. And $45.5 \%$ of them did not have the national psychological consultant certificate. Thus, primary and secondary schools should pay high attention in building up a scientific and effective training system for psychological teachers, especially in aspects of family education and counseling, individual/group counseling, mental health curriculum design and implementation, as well as academic development counseling [6].

Although 54.5\% of the psychological teachers did not attend any mental health related research project in the last three years, about $70 \%$ of them have the active willingness to participate in various trainings, seminars and research projects. Therefore, on the one hand, relevant state departments should provide more research funding to facilitate research activities of the psychological teachers. On the other hand, schools may establish research groups so that psychological teachers could easily communicate with each other about mental health issues. Schools may also connect psychological teachers' performance evaluations and promotions to scientific research task. In this way, scientific research on mental health education will be substantially promoted.
C. Expand the influence of school mental health education, improve the effectiveness of school counseling

The investigation showed that students with psychological problems tend to rely on self-adjustment and communications with friends. Only a small part of them will refer to their psychological teachers. This is especially the case in senior high school students. One reason for this phenomenon may be the academic stress and personality characteristics of adolescents. More importantly, it may also reflect the less awareness of school counseling in students, possibly due to the less level of attention schools have paid to mental health education and the insufficient propaganda. Accordingly, we suggest that schools should organize psychological health education activities among students, class teachers, and other subject teachers regularly. Moreover, different media such as school radio station, school TV station and school website, and a variety of lively and popular means such as psychological games and psychodrama should be utilized to publicize the effects of mental health education.

Finally, although most of the students have positive evaluations on individual counseling and mental health curriculum, there were significant differences of the evaluations between high and low level school students. This indicated the gap between the professional qualities and work effectiveness of the psychological teachers from schools of different levels. In addition to participate in various training programs to improve one's own professional quality, the psychological teachers should also actively communicate with students outside the classroom and the counseling room, for instance, through network and hotline. By establishing long-term and effective communication channels for students, the psychological teachers could better understand students' psychological problems, give them timely and constant psychological guidance, and eventually enhance the effectiveness of school counseling.

\section{Acknowledgment}

We thank all the teachers in the Institute of Educational Psychology and School Counseling of Beijing Normal University for their hard work in developing the set of questionnaires used in this study.

\section{References}

[1] S. J. Foster, "The relationship between professional identity and collective self-esteem in school counselors," (dissertation), University of New Orleans, 2010.

[2] W. Cai, and L. Yi, "An investigation on the present situation and professional development of psychological teachers in primary and secondary school in Changchun," Journal of ChangChun Education College, vol. 3, pp. 42-44, 2010.

[3] M. Liang, and L. Cheng, "Thoughts and suggestions on the consturctuon of psychological education teaching staff in primary and secondary school," Journal of Longyan University, vol. 28, pp. 113-116, 2010.

[4] Y. Tong, "Analysis on the professional characteristics of school psychologist in the united states," Chinese Journal of Special Education, vol. 8, pp. 24-26, 2005.

[5] American School Counselor Association. The ASCA national model: A framework for school counseling programs. Alexandria, VA: Author, 2003.

[6] H. Chen, and Y. Ye, "Cultivation, appointment and development trend of school psychologist in primary and secondary school in Taiwan," Mental Health Education in Primary and Secondary School, vol. 6, pp. 81-85, 2010. 